\title{
Long-term analysis of upper incisor crowding. A longitudinal study of orthodontically treated patients
}

\author{
Luis López-Areal ${ }^{1}$, Vanessa Paredes ${ }^{2}$, José-Luis Gandía ${ }^{3}$ \\ ${ }^{1}$ Orthodontist. Private practice in Bilbao. Master in Orthodontics. University of Valencia \\ ${ }^{2}$ Orthodontist. Assistant Professor. Doctor of Stomatology (Orthodontics teaching Unit) \\ ${ }^{3}$ Orthodontist. Professor of Stomatology (Orthodontics Teaching Unit). Director of Orthodontics Master at the University of \\ Valencia
}

Correspondence:

Ercilla, $42-6^{\circ} \mathrm{J}$

48011 Bilbao (Vizcaya), Spain

l.lopezareal@terra.es

Received: $26 / 05 / 2010$ Accepted: 26/08/2010

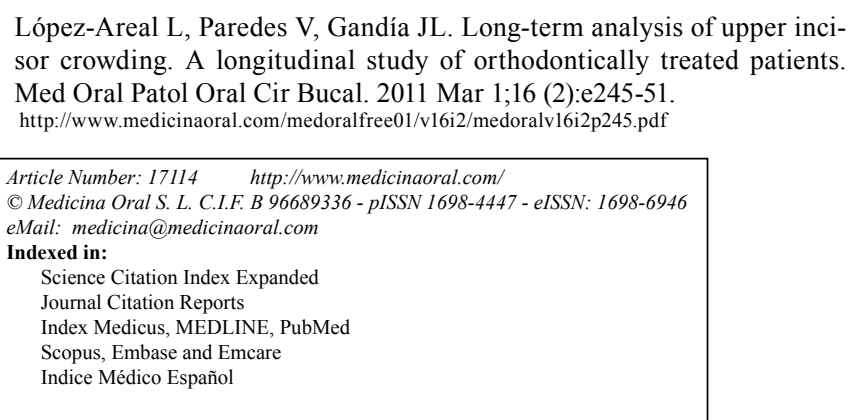

\begin{abstract}
Introduction: Although there are numerous studies in the literature on alignment stability in the lower arch, there are few referring to the upper arch. Aims: To assess upper arch stability (irregularity index, widths and length of arch, overjet and overbite) in orthodontically treated patients by comparing late incisor stability with the initial malocclusion and type pf treatment undertaken.

Study design: The study models of 51 patients, treated with or without extractions, were analysed at three different points in time: pre-treatment (T1), post-treatment (T2) and post-retention (T3) (average 5 years). The following parameters were measured: irregularity index, arch length, inter-canine and inter-molar widths, overjet and overbite.

Results: The results showed that upper incisor crowding relapses, although a net improvement is noted in comparison to the initial state both in cases treated with or without extractions. The arch length also relapses in both cases. The inter-canine and inter-molar widths as well as the overjet and overbite are stable in the long term. The long-term response of maxillary incisor alignment is unpredictable.

Conclusions: There is a statistically significant reduction in incisor irregularity, length and width of arch (inter-canine and inter-molar widths), whereas overjet and overbite undergo a reduction of little magnitude. No statistically significant correlation is noted between late incisor stability and the initial malocclusion or type of treatment.
\end{abstract}

Key words: Retention, relapse, stability, irregularity, alignment. 


\section{Introduction}

Upper incisor alignment is an essential aesthetic aim in orthodontic treatment. Different techniques and mechanics help to ensure that front teeth maintain an appropriate relationship so as to harmonise the most visible part of the dentition when speaking and smiling. The stability of dentary movement has scarcely been studied due to the difficulty of obtaining records from patients years after the retention stage has ended. Since Angle wrote in 1907 that "retention is very often little considered", published studies have been few in proportion to the importance of the subject.

The relapse of incisor crowding has been more deeply studied in the lower arch that in the upper arch, given that, as Little (1) says, "mandibular crowding is the predecessor of maxillary crowding".

Numerous factors have been invoked to account for alignment relapse in the long term. The first works published consider the maintenance of the bicanine diameter as the key to long term stability, although there are other factors such as late growth, size and shape of the incisors, among others, which can also have repercussions on relapse, the importance of one or another still not having been elucidated (2).

The results of longitudinal studies on orthodontic patients, as well as on untreated individuals, are similar, though to differing degrees. It is, therefore, difficult to assess whether the late changes that are registered in patients are due to the relapse of the orthodontic treatment, or if they form part of the overall process of development and maturation of the orofacial structures (3).

If one looks at several studies on the long-term development of untreated arches (3-5), as well as orthodontically treated ones $(1,6-8)$, one arrives at the conclusion that dentary arches progressively contract, both their longitudinal and transversal measurements decreasing, so causing incisor crowding. Likewise, it is considered that this is variable and unpredictable, no clinical, biometric or cephalometric variables being found that predict future development (1).

As we have said, the theory put forward is that changes occurring over time are of a similar nature whether the arches have been treated or not, although to a different degree. The tendency towards decreased size and crowding is maximum in cases treated with extractions and minimum in untreated occlusions. This different behaviour may originally be due to the magnitude of the initial crowding, which would be maximum in cases of extraction, intermediate in those treated without extraction and minimum in untreated occlusions.

Sinclair and Little (3) suggested that orthodontic treatment may act as an accelerator of the future changes that, physiologically, the maturing process would produce in the arches. This would explain how, in many studies, treated cases in general presented less stabil- ity than untreated individuals. The stability of the latter would be similar to that found in treated cases if longer term studies were undertaken.

The few studies on the relapse of upper incisor crowding do so as part of the study of both arches, observing post-retention crowding also in the upper arch in cases treated with and without extractions and without being able to find prognostic factors of its long-term evolution.

Therefore, the aims of this study were:

- To assess long-term upper arch alignment stability in orthodontically treated patients.

- To analyse the relationship between late incisor stability and clinical variables such as the initial malocclusion and type of treatment undertaken (with or without extractions).

- To study the relationship between late incisor stability and the odontometric parameters measured -irregularity index, widths and length of arch, overjet and overbite- at three points in time.

\section{Materials and Methods}

\section{-Sample}

The sample consisted of 51 patients; 35 women and 16 men. The mean age was 11 years 6 months at the beginning of treatment (T1), 15 years on completion of active treatment (T2) and 22 years for the final observation (T3). The duration of the different treatments was variable, although the average maintenance period was of two years one month. The mean post-retention period was of five years and two months. 34 of them were treated without extractions and 17 with. The distribution of the sample per malocclusions was as follows: $37 \%$ Class I (19 cases), 49\% Class II (12 class II- 1 cases and 13 class II- 2 cases) and 14\% Class III ( 7 cases). The patients had been treated by the same experienced orthodontist with standard arch edgewise technique and brackets with slot of 0.018 "x 0.025 ".

-Method

The plaster cast study models of each patient were measured by a single technician at three different points in time. The pre-treatment models (T1) were taken immediately before starting treatment; the post-treatment models (T2) at the moment of removing the brackets and post-retention models (T3) were taken at 5 years and two months (on average) after having removed the retainers.

Taken from the upper arch were each of the following measurements:

-Irregularity index (II)

As Little described, the irregularity index is the sum of the linear distances measured at the anatomic points of contact between the six front teeth.

-Arch Length (AL)

According to Nance, the arch length is the sum of the 
distances between the mesial point of contact between the upper first molar and the contact or the mean interincisor point from both sides.

-Inter-canine width (ICW)

This is the linear measurement between the cuspids of the contralateral upper canines or, in the event of presenting facet wear, the distance between the centre of the worn surfaces.

\section{-Inter-molar width (IMW)}

This is the linear measurement between the mesiovestibular cuspids of the first permanent upper molars.

-Overjet (OJ)

This is the linear distance between the edge of the most protruding upper central incisor and that of its antagonist measured parallel to the occlusal plane.

-Overbite $(O B)$

This is the linear distance of greatest vertical overlap of the central incisors. To obtain this, the incisal edge of the upper central incisor with the greatest vertical overlap to the labial surface of its antagonist or of the gum is projected using a fine marker pencil placed in the direction of the occlusal plane.

Measurements were undertaken using a digital Mitutoyo ${ }^{\circledR}$ calibrator with a precision of $0.01 \mathrm{~mm}$. Each model was measured twice by the same technician and, if there was any difference between the measurements greater than $0.5 \mathrm{~mm}$, the measurement was repeated.

The statistical analysis included, apart from the descriptive statistics, the following tests: test-t, Pearson's correlation coefficients, multiple regression analysis and variance analysis. Tests were considered significant when the null hypothesis could be rejected with a significance level of $\alpha=0.05$.

\section{Results}

\section{-Irregularity index (II)}

In this table (Table 1), a significant worsening of the late irregularity index (II) compared to the end of treatment (T3-T2 $=1.51 \mathrm{~mm}$ ) can be observed, even though there is a net improvement $(\mathrm{T} 3-\mathrm{T} 1=-7.05 \mathrm{~mm})$ if we compare it with the initial values before treatment. If we consider $5 \mathrm{~mm}$ of irregularity as the limit between the acceptable or unacceptable, out of our entire sample, 40 cases presented unacceptable irregularity at the beginning of treatment (II $>5 \mathrm{~mm}$ ), whereas only 6 maintained that clinically unacceptable irregularity in the long-term (IIT3).

We can observe the means and standard variations of the parameters studied when comparing cases treated with or without extractions. It can be seen that during the late stage (II.T3) the II in cases with extractions is greater, although without statistically significant differences.

There is no correlation between late incisor stability (II-T3) and the initial malocclusion.
Table 2 shows the possible correlations between later incisor stability (II-T3) and the odontometric variables studied -irregularity index, width and length of arch, overjet and overbite- at the three points in time. No clinically significant correlation was found with either of them except with irregularity at the end of treatment (II-T2). Hence, those parameters with the highest correlations were selected, a multiple regression analysis being applied in which the dependent variable was II-T3. A statistically significant association $(p=0.0014)$ was observed with irregularity at the end of treatment (IIT2), which suggests that late irregularity (II-T3) would be greater, the greater it is at the end of active treatnment (II-T2).

-Arch length (AL)

AL did not vary significantly during active treatment, although following the retention stage a significant reduction (AL T2-T3 $\approx-2 \mathrm{~mm}$ ) was observed.

A significant increase was observed during active treatment in cases treated without extractions (AL T1-T2 $=2.8 \mathrm{~mm}$ ) and a significant reduction in those treated with extractions (AL T1-T2 = -7 mm). In both cases a significant reduction took place following the retention stage, being greater in the case of those treated with extractions (AL T2-T3 $=-2.2 \mathrm{~mm}$ ).

In Classes II-2 both the increase during treatment (AL $\mathrm{T} 1-\mathrm{T} 2=4.7 \mathrm{~mm}$ ) and the post-retention relapse (AL T2$\mathrm{T} 3=-2.7 \mathrm{~mm}$ ) were statistically significant.

-Inter-canine width (ICW)

We observed a significant increase in the inter-canine width during the treatment stage (ICW T1-T2 $\approx 2.7$ $\mathrm{mm})$, this expansion also maintaining significance following retention (ICW T1-T3 $=2.3 \mathrm{~mm}$ ).

In cases with extractions, an increase took place during the active stage (ICW T1-T2 $=2.5 \mathrm{~mm}$ ) that remained largely stable. In cases without extractions, this distance also increased during treatment (ICW T1-T2 $=2.7 \mathrm{~mm}$ ) remaining stable following retention. The expansion obtained during treatment remains stable in the longterm.

-Inter-molar width (IMW)

The variation is very similar to that of the intercanine width. A slightly statistically significant increase is observed during treatment (IMW T1-T2 $=1.8 \mathrm{~mm}$ ) that remains stable as the relapse is very small (IMW T2-T3 $=-0.4 \mathrm{~mm}$ ).

In cases treated with extrtactions this parameter decreases during treatment (IMW T1-T2 $=-1.7 \mathrm{~mm}$ ) where for cases treated without extractions it increases during the same period (IMW T1-T2 = 3,6 mm). The final observation shows an increase (IMW T1-T3 = $3 \mathrm{~mm}$ ) in cases treated without extractions and a decrease in those treated with extractions (IMW T1-T3 $=-1.9 \mathrm{~mm}$ ). The stability of the changes is also notable with regard to the inter-molar width. 
Table 1. Cast measures and treatment (extraction vs. non extraction) * Statistically significant difference $(\mathrm{p} \leq=0.05)$. II $=$ irregularity index, $\mathrm{AL}=$ Arch Length, $\mathrm{ICW}=$ Intercanine Width, $\mathrm{IMW}=$ Intermolar Width, $\mathrm{OJ}=$ Overjet y $\mathrm{OB}=$ Overbite. Mean $\pm \mathrm{SD}$.

\begin{tabular}{|c|c|c|c|c|c|c|c|}
\hline Variable & Treatment & $\begin{array}{l}\text { Pretreatment } \\
\text { T1 } \\
\text { Mean } \pm \text { SD }\end{array}$ & $\begin{array}{l}\text { Postreatment } \\
\text { T2 } \\
\text { Mean } \pm \text { SD }\end{array}$ & $\begin{array}{l}\text { Postretencion } \\
\text { T3 } \\
\text { Mean } \pm \text { SD }\end{array}$ & $\begin{array}{l}\text { T2-T1 } \\
\text { Mean } \pm \text { SD }\end{array}$ & $\begin{array}{l}\text { T3-T2 } \\
\text { Mean } \pm S D\end{array}$ & $\begin{array}{l}\text { T3-T1 } \\
\text { Mean士SD }\end{array}$ \\
\hline \multirow[t]{3}{*}{ II } & Total & $9.87 \pm 4.46$ & $1.30 \pm 1.24$ & $2.82 \pm 2.01$ & $-8.56 \pm 4.2$ & $1.51 \pm 1.75^{*}$ & $-7.05 \pm 4.37^{*}$ \\
\hline & no extr & $8.60 \pm 3.61$ & $1.37 \pm 1.35$ & $3.03 \pm 2.00$ & $-7.22 \pm 3.4$ & $1.65 \pm 1.74^{*}$ & $-5.57 \pm 3.47^{*}$ \\
\hline & extr & $12.41 \pm 5.02$ & $1.16 \pm 1.00$ & $2.41 \pm 2.03$ & $-11.24 \pm 4.3$ & $1.24 \pm 1.79^{*}$ & $10.00 \pm 4.58^{*}$ \\
\hline \multirow[t]{3}{*}{$\mathbf{A L}$} & Total & $68.68 \pm 5.22$ & $68.30 \pm 7.16$ & $66.52 \pm 6.60$ & $-0.47 \pm 6.4$ & $-1.78 \pm 1.99^{*}$ & $-2.25 \pm 5.95^{*}$ \\
\hline & no extr & $69.66 \pm 5.32$ & $72.48 \pm 3.83$ & $70.30 \pm 3.58$ & $2.82 \pm 4.36$ & $-2.18 \pm 2.22^{*}$ & $0.63 \pm 4.32$ \\
\hline & extr & $67.02 \pm 4.66$ & $59.95 \pm 4.32$ & $58.97 \pm 4.33$ & $-7.07 \pm 4.5$ & $-0.97 \pm 1.09^{*}$ & $-8.04 \pm 4.33^{*}$ \\
\hline \multirow[t]{3}{*}{ ICW } & Total & $31.94 \pm 2.33$ & $34.60 \pm 1.74$ & $34.27 \pm 1.71$ & $2.66 \pm 2.44$ & $-0.32 \pm 0.94^{*}$ & $2.33 \pm 2.34^{*}$ \\
\hline & no extr & $31.96 \pm 2.36$ & $34.70 \pm 1.80$ & $34.49 \pm 1.71$ & $2.74 \pm 2.38$ & $-0.20 \pm 0.72$ & $2.53 \pm 2.26^{*}$ \\
\hline & extr & $31.89 \pm 2.34$ & $34.40 \pm 1.66$ & $33.85 \pm 1.68$ & $2.50 \pm 2.63$ & $-0.55 \pm 1.28$ & $1.95 \pm 2.51^{*}$ \\
\hline \multirow[t]{3}{*}{ IMW } & Total & $49.36 \pm 2.69$ & $51.17 \pm 3.78$ & $50.75 \pm 3.59$ & $1.80 \pm 3.68$ & $-0.42 \pm 1.25^{*}$ & $1.38 \pm 3.43^{*}$ \\
\hline & no extr & $49.39 \pm 2.77$ & $52.97 \pm 3.06$ & $52.42 \pm 2.76$ & $3.57 \pm 2.82$ & $-0.55 \pm 1.37^{*}$ & $3.02 \pm 2.46^{*}$ \\
\hline & extr & $49.31 \pm 2.59$ & $47.58 \pm 2.23$ & $47.40 \pm 2.59$ & $-1.72 \pm 2.4$ & $-0.17 \pm 0.95$ & $-1.90 \pm 2.67^{*}$ \\
\hline \multirow[t]{3}{*}{ OJ } & Total & $3.50 \pm 3.10$ & $2.30 \pm 0.85$ & $2.32 \pm 1.01$ & $-1.14 \pm 2.9$ & $-0.03 \pm 0.83$ & $-1.17 \pm 2.82^{*}$ \\
\hline & no extr & $4.12 \pm 3.22$ & $2.52 \pm 0.82$ & $2.45 \pm 1.04$ & $-1.59 \pm 3.1$ & $-0.07 \pm 0.93$ & $-1.64 \pm 2.98^{*}$ \\
\hline & extr & $2.26 \pm 2.48$ & $2.02 \pm 0.81$ & $2.06 \pm 0.91$ & $-0.23 \pm 2.2$ & $0.04 \pm 0.62$ & $-0.19 \pm 2.24$ \\
\hline \multirow[t]{3}{*}{$\overline{O B}$} & Total & $3.92 \pm 3.52$ & $3.04 \pm 1.11$ & $3.33 \pm 1.21$ & $-0.88 \pm 3.6$ & $0.28 \pm 1.15$ & $-0.59 \pm 3.41$ \\
\hline & no extr & $4.69 \pm 3.38$ & $3.13 \pm 1.14$ & $3.26 \pm 1.27$ & $-1.55 \pm 3.3$ & $0.12 \pm 1.22$ & $-1.43 \pm 3.13^{*}$ \\
\hline & extr & $2.39 \pm 3.39$ & $2.86 \pm 1.06$ & $3.48 \pm 1.10$ & $0.46 \pm 3.9$ & $0.62 \pm 0.93^{*}$ & $1.08 \pm 0.40$ \\
\hline
\end{tabular}


Table 2. Multiple regression analysis (Total sample). Dependent variable: II-T3. *Statisticallysignificant difference $(\mathrm{p} \leq=0.05)$. II $=$ irregularity index, $\mathrm{AL}=$ Arch Length, $\mathrm{ICW}=$ Intercanine Width and $\mathrm{OJ}=$ Overjet.

\begin{tabular}{|c|c|c|}
\hline Independent variable & Correlation $(\mathbf{r})$ & Probability (p) \\
\hline II-T2 & 0.50 & $0.001^{*}$ \\
\hline AL T2-T1 & 0.35 & 0.779 \\
\hline AL T3-T1 & 0.34 & 0.850 \\
\hline OJ T3-T1 & 0.34 & 0.088 \\
\hline OJ T2-T1 & 0.27 & 0.749 \\
\hline OJ T1 & -0.42 & 0.0856 \\
\hline ICW T3-T1 & -0.30 & 0.658 \\
\hline ICW T2-T1 & 0.30 & 0.828 \\
\hline R & $\mathrm{R}^{2}$ & $\mathrm{P}$ \\
\hline 0.67 & 0.45 & 0.0007 \\
\hline
\end{tabular}

\section{-Overjet (OJ)}

Overjet diminishes slightly and significantly during active treatment, especially in Classes II-1 remaining practically unchanged during the retention stage.

-Overbite (OB)

Overbite diminshes by nearly $1 \mathrm{~mm}$ during active treatment, slightly increasing following the retention stage, but without reaching the initial values.

The group treated with extractions presents a greater relapse, although not significantly.

Class II malocclusions register initial values higher than Class I, so also present significantly greater overall variations and corrections, especially with regard to Classes II-2.

\section{Discussion}

The changes in class II of our study are similar to the results of Uhde \& cols. (6) in their study on 72 patients treated with or without extractions 20 years after retention. Both in our study and in the previous one, a slight relapse of the irregularity index is noted that is less than the improvement achieved during the active Orthodontic treatment. This net gain is not as clear as that referred to by Sadowsky \& Sakols (9) on a sample of 96 patients treated with or without extractions 20 years after retention, where no patient was found with a longterm crowding greater or equal to $3 \mathrm{~mm}$. In our study we found 22 patients that exceeded that value, six of whom even exceeded the limit of what is considered clinically acceptable (II $<5 \mathrm{~mm}$.).

Comparing cases treated with or without extractions, a higher irregularity index was noted in the late stage (II-T3) in cases with extractions, although without statistically significant differences, as Uhde \& cols. (10) found. These authors (10), in a simple correlation analysis reached the conclusion that the relapse of irregular- ity is significantly related to the decrease in the bicanine width during active treatment, even though that correlation is low $(0.38)$ and very similar to that found in this study (0.29), not approaching that which is considered clinically significant $(r \geq 0,60)$.

Studies on the stability of alignment in the lower arch are more numerous than those referring to the upper arch. However, the prestigious studies of the University of Washington led by Little $(1,8)$ and undertaken over more than 35 years on records of more than 600 patients with post-retention periods of more than 10 years do not find any prognostic factor for late crowding.

As regards the upper arch, the results of this study show that the irregularity index value on completion of treatment (II-T2) is associated with its late value (II-T3) as can be observed from the multiple regression analysis. These results suggest that the greater the irregularity on completing the period of active treatment, the greater will be the relapse. From that can be deduced the need to finish incisor alignment with the greatest of care if we wish the case to be more stable over the passage of time.

The decrease of AL in our work is significantly greater in cases treated without extractions, just as the work of Little $(1,10)$ on the lower arch, Bishara \& cols. (11) on the upper arch in untreated individuals and Little \& cols. (12) on the lower arch in 26 cases checked after a more than 6 years post-retention period and treated without extractions, documented.

In the three malocclusions studied, a reduction in the AL was observed following the retention period. This reduction is more apparent in Class II-2 (statistically significant compared with Class I) and the explanation could be the fact of having been treated without extractions. The net variation of the arch length in Class I is a reduction, due to the type of treatment employed. In 
Class II-1, this overall reduction is lesser as the initial values, very high due to the effect of their characteristic overjet, contribute to it. However, in Classes II-2, an overall increase takes place due to the increase in the arch length during the active treatment stage.

The ICW increased by around $3 \mathrm{~mm}$ during active treatment; perhaps due to the characteristics of the sample, given that part of it presented mixed dentition at the beginning of the treatment. On eruption of the canines, an increase in ICW takes place of some $2 \mathrm{~mm}$, as has been traditionally described. Following retention a slight decrease was noted similar to that found in other studies both on treated patients, such as that of El-Mangoury (13) on 50 cases treated with or without extractions and checked after more than 2 years after retention; that of the above-mentioned Uhde \& cols. (6), or in the work of Bishara \& cols. (14) referring to the evolution of untreated arches.

No significant differences were found in the stability of the ICW depending on treatment type, unlike other studies such as those already mentioned of Uhde \& cols., as well as that of Gianelly (15), which compared the inter-canine and inter-molar width in 50 cases treated with or without extractions at the beginning and end of the treatment.

With regard to the variation pattern in cases treated with extractions, our results coincide with those of Bishara \& cols. (16) in their study on 30 patients treated with extractions and checked a little more than a year after retention, where an increase in ICW was noted during the active treatment and then a slight late relapse.

The IMW behaves like the ICW; the decrease following the retention stage has been observed by other authors already mentioned such as Uhde \& cols. (6). The subsamples treated with or without extractions show variations similar to the studies of Uhde \& cols. and Gianelly (15).

Our results show a lesser relapse of overjet than that observed by other authors such as Glenn \& cols. (7), Sadowsky \& Sakols (9), Bishara \& cols. (16), or Shields $\&$ cols. (17), although those results stemmed from initial values greater than those that we measured.

Cases treated without extractions show, on completion of the treatment, a significantly greater overjet than the sub-sample treated with extractions. These results do not coincide with those of Uhde \& cols. (6) in which greater relapse values were noted in cases treated with extractions, although not significantly.

The tendency to overjet relapse is common in the three types of malocclusion studied and there are no significant differences between them, as El- Mangoury (13) found, even although other authors such as Uhde \& cols. found greater relapse values in class II.

During active treatment a decrease in $\mathrm{OB}$ is noted which relapses, although not to initial values. These re- sults, similar for many of the authors consulted, have traditionally led to recommending over-correction of the OB, although Canut and Arias (18), in their work on 30 cases of class II-2 treated and assessed after more than 3 years following retention, did not find any better results in the over-corrected group.

OB relapse is noted in many studies such as Uhde \& cols and El-Mangoury (13); even though for others, such as Sadowsky and Sakols (9), overbite does improve over time in some cases.

In this study, the post-retention changes of $\mathrm{OB}$ are not significantly related with the type of treatment employed, so agreeing with the works of authors such as Berg (19); although Uhde \& cols. (6) do indeed find greater relapse in cases treated with extractions, though not significant.

Both in our study and in most of the studies consulted, such as Uhde \& cols; Glenn and cols. (7) or Little and cols. (20), no significant differences are noted in terms of OB relapse depending on the type of initial malocclusion.

The patient must be adequately informed before starting the orthodontic treatment of the strong posibility of a relapse in incisor crowding, explaining to him or her that the only way of ensuring an acceptable dental alignment is by means of retention, either permanent of semi-permanent.

\section{References}

References with links to Crossref - DOI

1. Little RM. Stability and relapse of mandibular anterior alignment: University of Washington studies. Semin Orthod. 1999;5:191-204.

2. Blake M, Bibby K. Retention and stability: a review of the literature. Am J Orthod Dentofacial Orthop. 1998;114:299-306.

3. Sinclair PM, Little RM. Maturation of untreated normal occlusions. Am J Orthod. 1983;83:114-23.

4. Tibana RH, Palagi LM, Miguel JA. Changes in dental arch measurements of young adults with normal occlusion--a longitudinal study. Angle Orthod. 2004;74:618-23.

5. Buschang PH, Shulman JD. Incisor crowding in untreated persons 15-50 years of age: United States, 1988-1994. Angle Orthod. 2003;73:502-8.

6. Uhde MD, Sadowsky C, BeGole EA. Long-term stability of dental relationships after orthodontic treatment. Angle Orthod. 1983;53:240-52.

7. Glenn G, Sinclair PM, Alexander RG. Nonextraction orthodontic therapy: posttreatment dental and skeletal stability. Am J Orthod Dentofacial Orthop. 1987;92:321-8.

8. Little RM. Stability and relapse: early treatment of arch length deficiency. Am J Orthod Dentofacial Orthop. 2002;121:578-81.

9. Sadowsky C, Sakols EI. Long-term assessment of orthodontic relapse. Am J Orthod. 1982;82:456-63.

10. Little RM. Stability and relapse of dental arch alignment. Br J Orthod. 1990;17:235-41.

11. Bishara SE, Jakobsen JR, Treder J, Nowak A. Arch length changes from 6 weeks to 45 years. Angle Orthod. 1998;68:69-74.

12. Little RM, Riedel RA, Stein A. Mandibular arch length increase during the mixed dentition: postretention evaluation of stability and relapse. Am J Orthod Dentofacial Orthop. 1990;97:393-404.

13. El-Mangoury NH. Orthodontic relapse in subjects with varying degrees of anteroposterior and vertical dysplasia. Am J Orthod. 1979;75:548-61.

14. Bishara SE, Jakobsen JR, Treder J, Nowak A. Arch width changes 
from 6 weeks to 45 years of age. Am J Orthod Dentofacial Orthop. 1997;111:401-9.

15. Gianelly AA. Arch width after extraction and nonextraction treatment. Am J Orthod Dentofacial Orthop. 2003;123:25-8.

16. Bishara SE, Chadha JM, Potter RB. Stability of intercanine width, overbite, and overjet correction. Am J Orthod. 1973;63:588-95.

17. Shields TE, Little RM, Chapko MK. Stability and relapse of mandibular anterior alignment: a cephalometric appraisal of first-premolar-extraction cases treated by traditional edgewise orthodontics. Am J Orthod. 1985;87:27-38.

18. Canut JA, Arias S. A long-term evaluation of treated Class II division 2 malocclusions: a retrospective study model analysis. Eur J Orthod. 1999;21:377-86.

19. Berg R. Stability of deep overbite correction. Eur J Orthod. 1983;5:75-83.

20. Little RM, Wallen TR, Riedel RA. Stability and relapse of mandibular anterior alignment-first premolar extraction cases treated by traditional edgewise orthodontics. Am J Orthod. 1981;80:349-65.

\section{Acknowledgments}

Our thanks to Professor Jose Antonio Canut (in memoriam) for the sample provided for tis study. 